\title{
La gestión electrónica de la información y docu- mentación administrativa en los municipios españoles
}

\author{
Carmen Gómez Camarero \\ Dpto. Filología Griega, Estudios Árabes, \\ Lingüística y Documentación \\ Universidad de Málaga
}

\subsection{Resumen}

Se realiza una aproximación a la prestación de servicios de información y documentación administrativa por los municipios españoles a través de la World Wide Web. Para ello, se analiza la información ofrecida en las páginas web de una muestra representativa de ayuntamientos. En particular se estudio la información sobre el municipio y los diferentes servicios municipales, distinguiendo la dirigida a los visitantes y la orientada específicamente a los ciudadanos; la posibilidad ofrecida al ciudadano de comunicarse con las administraciones municipales a través de los servicios de correo electrónico, listas de discusión o chats; y, por último, el estado de desarrollo de la "administración virtual", esto es, de la posibilidad de realizar trámites administrativos a través de Internet.

Palabras clave: Información y documentación administrativa. Administración virtual. Entidades locales. World Wide Web. España.

\subsection{Abstract}

An approximation to the Spanish council governments information and documentation services on the World Wide Web is offered. The study is based on a representative sample and considers mainly the information offered to visitors and citizens on the town and its council services, the possibility of communication with the administration by e-mail, chats and discussion lists, and the level of development of the so-called virtual administration, that is, the possibility of undertaking administrative acts through the Internet.

Keywords: Governmental information and documentation. Virtual administration. Local entities. World Wide Web. Spain. 


\section{Introducción}

El continuo desarrollo de las Tecnologías de la Información y la Comunicación (TIC) está produciendo nuevos modos de funcionamiento en el seno de las Administraciones Públicas, cuyas consecuencias afectan de manera directa a la relación entre éstas y los ciudadanos, y ello puede apreciarse en dos niveles.

En primer lugar, las nuevas tecnologías, por su capacidad de tratamiento de la información, facilitan y agilizan la gestión interna de las actividades de la Administración y proporcionan un marco de trabajo caracterizado por la colaboración, la cooperación y la información compartida. Estos elementos constituyen la clave de la nueva cultura administrativa en la que se otorga una especial atención al concepto de Gestión del Conocimiento (GC) y a la consideración de este nuevo concepto, el Conocimiento, como un valor estratégico y un recurso básico de la gestión institucional (López Liborio, 2000). El nuevo paradigma de la GC pretende la incorporación de los procesos de generación, captura, estructuración, asimilación y reutilización de los conocimientos en la gestión administrativa, procesos que adquieren toda su dimensión gracias al soporte de las tecnologías de la información. Con este fin, se utilizan diferentes medios como las redes, los servicios de Internet o los sistemas de información compartidos que permiten aprovechar los conocimientos comunes en diferentes áreas de gestión, racionalizar las actividades, mejorar la productividad y establecer nuevas vías de comunicación posibilitando un mejor entendimiento tanto a nivel interno como externo.

En segundo lugar, las TIC constituyen un valioso instrumento en manos de las administraciones públicas para cumplir con su propósito de construir una Administración orientada a los ciudadanos, en una doble faceta:

$1^{\circ}$ La prestación de unos servicios de calidad, adaptados a las nuevas necesidades y expectativas de una sociedad en pleno cambio tecnológico.

$2^{\circ}$ La comunicación entre la Administración y los ciudadanos, que han visto ampliadas las vías de acceso a la información y de comunicación.

Así por ejemplo, la organización de la información administrativa en bases de datos estructuradas e interrelacionadas va a posibilitar una consulta sencilla y rápida, tanto por el personal público como por el ciudadano. O la informatización de los procedimientos administrativos, previa simplificación de los mismos (1), con el consiguiente beneficio para los ciudadanos, los cuales podrán obtener información, y al mismo tiempo, gestionar sus procedimientos obteniendo, cumplimentando y enviando de forma telemática los impresos y documentos correspondientes. De igual modo, podrán consultar en cualquier momento, el estado de tramitación de un proceso determinado.

Se podría decir que en un primer nivel de comunicación, la administración utiliza las TIC como un mecanismo adicional de transmisión del conocimiento 
junto a los sistemas tradicionales de información a los ciudadanos, como las Oficinas de Información o los Puntos de Información y Atención al Ciudadano (PIAC), o con la misma finalidad, las publicaciones y folletos divulgativos. Así los ciudadanos, a través de las páginas web creadas por los distintos organismos públicos, pueden también tener acceso a información relevante relativa a los mismos, conocer las principales líneas de actuación de las diferentes organizaciones y estar al tanto de los servicios que éstas prestan sin tener que desplazarse al organismo en cuestión. Pero esta información, que podría denominarse "estática" está ampliándose con nuevos estadios de comunicación, interactivos y participativos, que dinamizan las relaciones entre Administración y administrados a través de la red y que están configurando la "teleadministración", la cual se está implantando de forma creciente en las diferentes administraciones españolas (Central, Autonómica y Local).

Es precisamente este último aspecto, el de la comunicación interactiva entre la administración y los ciudadanos a través de la Red, el que vamos a tratar de definir en este trabajo, y más concretamente la administración local. Con este fin hemos escogido un conjunto de municipios españoles para analizar la prestación de servicios de información y documentación que ofrecen en sus páginas web, y presentar un panorama de la diversidad de iniciativas desarrolladas.

La muestra objeto de estudio procede del directorio de municipios con sitio web que proporciona el Ministerio de Administraciones Públicas en su página http://www.map.es, que nos lanza directamente hacia los municipios reseñados.

\section{Estado de la cuestión: información municipal en la red}

Las páginas web de los municipios españoles presentan una gran diversidad a la hora de proporcionar información a los ciudadanos, y la mayor complejidad o la calidad de las prestaciones ofrecidas no depende exclusivamente de la importancia del municipio o del número de habitantes. Un primer aspecto que hay que comentar es la autoría de las páginas, que en ciertos casos determina los contenidos de las mismas. Así, encontramos páginas realizadas por los propios ayuntamientos; sitios web diseñados por las Oficinas de Turismo; Diputaciones que se encargan de crear un formato único para todos sus municipios, como es el caso de la Diputación de Alicante o Albacete; e incluso alguna creada por iniciativa personal. Las más elaboradas suelen corresponder a aquellas que forman parte de algún proyecto tecnológico fomentado por la iniciativa de la administración local o autonómica con el objetivo de impulsar el desarrollo de la Sociedad de la Información entre los ciudadanos.

En esta situación podemos encontrar el proyecto Infoville en la Comunidad Valenciana (http://www.infoville.net), que se lleva a cabo en el seno del Plan de 
Modernización de las Administraciones Públicas de la Generalitat Valenciana desde 1996. Los municipios que forman parte de esta red proporcionan, a través de sus páginas web, un importante conjunto de servicios electrónicos que afectan a diversos sectores de la colectividad: administración, sanidad, educación, comercio, ocio, etc., de manera que los habitantes de estos municipios pueden leer el periódico local, consultar las notas de sus hijos, pedir cita en el médico e incluso visitarlo mediante videoconferencia, pagar sus impuestos o comprar en cualquier tienda desde sus ordenadores personales. Infoville ha hecho posible la "ciudad digital" o la "ciudad virtual", es decir, una estructura electrónica que aloja sitios web, tanto públicos como privados, y que ofrece tanto información general y administrativa como servicios electrónicos varios.

Otras iniciativas de este tipo podemos encontrarlas en Cataluña, donde existe un consorcio de municipios llamado Localret (http://www.localret.es) dedicado al desarrollo de las redes y los servicios telemáticos, y creado a iniciativa de la Federació de Municipis de Catalunya (FMC) y la Associació Catalana de Municipis (ACM). Integra en la actualidad un total de 745 ayuntamientos catalanes que agrupan el 97,5\% de la población de la población de Cataluña. Uno de los objetivos principales de Localret es representar los intereses de los municipios ante los órganos políticos y económicos donde se toman las decisiones que afectan a la legislación y ordenación de las telecomunicaciones, es decir, ante las administraciones de la Unión Europea, del gobierno español y de la Generalitat catalana. Por otra parte, presta servicios de asesoramiento técnico a los municipios interesados, organiza actividades formativas y de divulgación para facilitar la introducción de las nuevas tecnologías en el ámbito de la gestión municipal, pone en funcionamiento experiencias piloto, y trata de concienciar a los municipios de las posibilidades de Internet para llevar a cabo una gestión eficaz de la información municipal a través de una red coordinada de todos los municipios implicados.

Otro es el caso de Animsa (Asociación Navarra de Informática Municipal, S.A.) (http://www.animsa.es), una sociedad pública interlocal, constituida en 1985 a iniciativa de los Ayuntamientos de Pamplona y Lodosa y que agrupa en la actualidad a un centenar de Entidades Locales de Navarra. El objetivo de esta sociedad es "establecer las mejores condiciones para el acceso de las Entidades Locales a la informática de gestión y a sistemas de ayuda a la decisión, que les permitan una mejor atención de sus necesidades y ejercicio de sus competencias". Con esta finalidad, se dedican a crear y desarrollar sistemas informáticos e Intranets, así como cursos de formación y capacitación de usuarios.

En otra línea se sitúan algunos municipios de los que puede decirse que se encuentran casi en las primeras fases de la gestión de la información suministrada electrónicamente, y es el caso de aquellas páginas web que ofrecen una información mínima a los ciudadanos. 
En lo que respecta al diseño de los sitios web municipales, apreciamos también una gran variedad, y en este caso, la mayor o menor calidad sí parece estar en relación con el desarrollo tecnológico de los administradores de la página o de la política adoptada por el ayuntamiento en el campo de las nuevas tecnologías de la información y la comunicación. Por ejemplo, sería el caso de aquellos municipios que han adoptado una política de calidad y mejora continua de los servicios que prestan, y que por lo tanto, utilizan la red como una herramienta más de prestación de servicios de calidad y atención al ciudadano, como por ejemplo el Ayuntamiento de Lleida, que pone a disposición de sus vecinos en la página web las Cartas de Servicio de cada uno de los Departamentos municipales.

Las páginas web de estos y otros ayuntamientos presentan en general un aspecto bastante atractivo que incita a visitar las secciones que incorporan. Además para facilitar la navegación al visitante incluyen valiosas estrategias de navegación como pueden ser los mapas de los contenidos o/y los menús fijos en todas las páginas, que evitan la sensación de desorientación que pudiera producirse en cualquier momento - Ayuntamientos de Badalona (Barcelona), Baiona (Pontevedra), Bullas (Murcia), o Monforte de Lemos (Lugo)—, o buscadores que facilitan la recuperación de los datos del sitio web gracias a la creación de bases de datos propias. Algunos incluyen información adicional que también puede servir de ayuda al ciudadano en forma de FAQs (Frequently Asked Questions), es decir, las dudas más frecuentes que se le pueden plantear al ciudadano que visita las páginas, ya sean relativas a la estructuración de los contenidos o a información general sobre los servicios municipales - Ayuntamientos de Villanueva de la Cañada (Madrid), o Barrika (Vizcaya).En otro sentido, debemos mencionar la preocupación de los ayuntamientos por valorar la incidencia que sus sitios web tienen sobre sus ciudadanos. Por este motivo, algunas páginas incluyen contadores - Ayuntamiento de Alcañiz (Teruel)— que permiten elaborar estadísticas de visitantes, libros de visita donde es posible opinar sobre lo que se ha visto —Ayuntamiento de Cehegín (Murcia)—, o incluso encuestas de evaluación sobre los contenidos de la web - Ayuntamiento de Vilarderós (Orense), Ayuntamiento de Pamplona.

En definitiva, entre unos casos, de amplio desarrollo tecnológico, y otros mínimos, existe una variada gama de servicios electrónicos municipales y sobre ellos vamos a incidir.

\section{Tipologías de servicios de información electrónicos}

De forma general, podríamos establecer una clasificación de los servicios proporcionados por las páginas web de los municipios españoles analizados, en función del tipo de información suministrado, el perfil de los usuarios a los que va dirigida y las herramientas o servicios ofrecidos.

Scire. $7: 1$ (en.-jun. 2001) 69-88. 


\subsection{Información sobre la ciudad}

Internet permite una difusión rápida y económica de las informaciones, y a la vez, rompe con el concepto de espacio al poder difundirse más allá de las fronteras geográficas, no ya sólo locales, sino nacionales y mundiales. Por lo tanto, se trata de un medio idóneo para dar a conocer las riquezas geográficas, culturales y artísticas de la localidad. Así pues, en este primer apartado de información que los municipios presentan sobre su ciudad, se impone una primera distinción entre la que ofrecen a los propios ciudadanos del municipio y aquella otra destinada a los posibles visitantes y turistas, nacionales o extranjeros.

a. Información para el visitante

b. Información al ciudadano

Algunos ejemplos de esta distinción:

- Se da el caso de que en ciertas páginas la información turística es la más relevante, dejando una información mínima o incluso nula para los residentes, como ocurre en el caso del Ayuntamiento de Marbella, cuya página ha sido elaborada por la Oficina de Turismo, y por tanto, sus informaciones van dirigidas con exclusividad a los intereses de los turistas.

- O el ejemplo de la página del Ayuntamiento de Baeza, que está dedicada por completo a presentar las riquezas de su patrimonio artístico y cultural, y sólo ofrece la dirección postal y el teléfono del ayuntamiento como información municipal, a pesar de que la autoría es de este organismo.

- Por su parte, los Ayuntamientos de Jerez o de Zamora, organizan claramente desde el principio las informaciones dedicadas a los visitantes y aquellas destinadas a los habitantes de la localidad, de manera que resulta fácil para el navegante optar por el apartado que le interesa.

Generalmente, el tipo de información que ofrecen los ayuntamientos en este aspecto se pueden clasificar en:

a) Información de tipo geográfico, turístico, cultural y artístico, nomalmente proporcionada en varios idiomas además del castellano o el idioma de la comunidad autónoma; principalmente en inglés, aunque podemos encontrar también algunas en francés o en alemán. Incluyen además datos geográficos, climáticos, de población; patrimonio artístico (museos, monumentos, visitas artísticas); gastronomía; fiestas y tradiciones populares; información turística y hotelera (hoteles, campings, turismo rural, restaurantes, etc.); y deportes, ocio.

b) Información concerniente a la vida de la comunidad: actividades culturales y artísticas (agenda cultural), horario de medio de transportes urbanos, culto religioso, farmacias de guardia, etc. 
Algunos ejemplos de este tipo de informaciones:

- El sitio web de Alcalá de Henares informa ampliamente al navegante sobre los horarios de cualquier medio de transporte que pueda llevar a la ciudad. También aquí el visitante puede encontrar las farmacias de guardia o el horario de los cultos religiosos celebrados en la ciudad.

- El Ayuntamiento de Tomelloso (Ciudad Real) nos ofrece la posibilidad de visitar virtualmente el Museo de Antonio López Torres.

- La agenda cultural del Ayuntamiento de Durango está organizada como una base de datos que permite consultar a qué tipo de actividad queremos acudir y los días que preferimos.

- En Sevilla, es posible hacer una visita virtual por el Parque María Luisa.

- La ciudad de Segovia informa cuidadosamente a los visitantes mediante directorios muy informativos sobre hospitales y clínicas, horarios de transportes, restaurantes, alojamientos, monumentos y museos (Fig.1).

- El sitio web del Ayuntamiento de Baiona (Pontevedra) proporciona una seleccionada "Guía de compra", clasificada por categorías temáticas y que sirve al ciudadano para obtener todos los detalles relativos a locales comerciales de todo tipo (peluquerías, librerías, tiendas de automóviles, talleres,

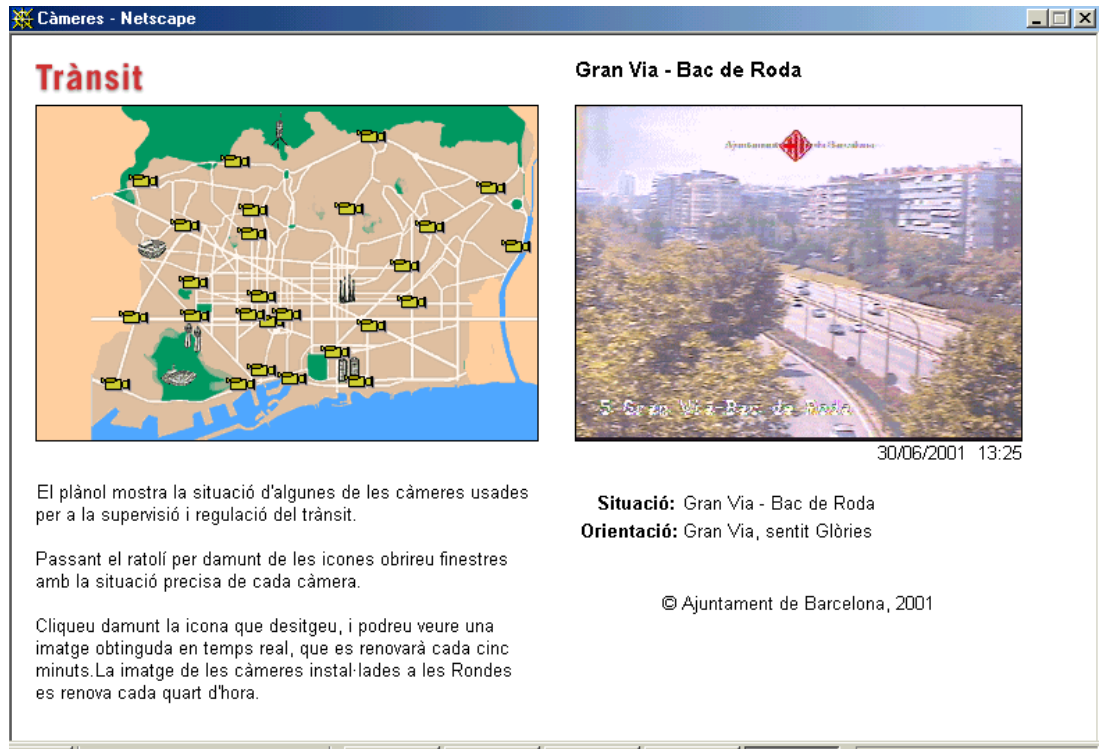

Fig. 1. Información sobre el tráfico en Barcelona

Scire. $7: 1$ (en.-jun. 2001) 69-88. 
de alimentación, zapaterías, etc.), entidades sanitarias, educativas, financieras y deportivas, transportes, asesorías jurídicas e incluso lugares de ocio, como discotecas.

- Zarautz (Guipúzcoa) nos propone un callejero interactivo en su sitio web. Y el Ayuntamiento de Oviedo, un paseo virtual por sus calles. Por su parte, la página web del Ayuntamiento de Écija ofrece un video del municipio.

- Una de las prestaciones electrónicas del Ayuntamiento de Barcelona (Fig. 1) es la visualización en tiempo real de la densidad del tráfico en las más importantes arterias de la ciudad, a través de las imágenes obtenidas mediante cámaras de video situadas en esos emplazamientos. El ciudadano puede observar el estado del tráfico con imágenes que cambian cada cinco minutos.

\subsection{Información sobre servicios municipales}

Las páginas web de los municipios españoles sirven como medio de difusión para la administración municipal, al ser utilizadas tanto como servicio de información como de tablón de anuncios para dar a conocer las novedades relativas a las ordenanzas y leyes municipales o a otros asuntos que conciernen la vida cotidiana de sus ciudadanos.

Veamos qué tipo de informaciones suele ofrecerse:

a) Información acerca de la constitución y estructura del municipio, con una descripción de funciones: órganos municipales, equipo de gobierno.

b) Información sobre servicios municipales: descripción y funciones. Se ofrece en ocasiones un directorio con los datos de contacto: teléfonos, correos electrónicos, dirección postal, y horarios de atención al público.

c) Información tributaria-fiscal, especialmente sobre impuestos municipales y calendario del contribuyente. Se trata del tipo de información más generalizado en los sitios web de los ayuntamientos, donde se indican los plazos y lugares de pago.

d) Tablón de anuncios: informaciones varias, como oferta de empleo, agenda cultural, deportiva, concursos, licitaciones, contratación de obras, exámenes y oposiciones. En definitiva, el tablón de anuncios se convierte, para algunos sitios web, en la ubicación idónea de informaciones que no han podido clasificarse en otras secciones.

e) Servicio de atención al ciudadano. En este apartado son tan diversas las informaciones como las formas de presentación. En algunos casos, se ofrece la posibilidad de recibir una información personalizada de la administración mediante el correo electrónico o un formulario a cumplimentar, y en otros, sólo se proporciona información general. 
f) Información sobre trámites administrativos: La descripción de todos los procedimientos municipales y los pasos a seguir para iniciarlos están a la disposición de los ciudadanos que consulten esta sección — presente en algunos sitios web municipales-, a veces en bases de datos fácilmente manejables y otras veces, clasificados cuidadosamente. Entre los trámites referenciados se encuentra una diversa tipología: solicitud de empadronamiento, solicitud de domiciliación bancaria de impuestos municipales, de certificados de convivencia, residencia, etc.

g) Información sobre ordenanzas y normativa municipal: estas informaciones pueden hallarse bien a texto completo, bien en archivos que pueden recuperarse desde un ordenador personal, u organizadas en bases de datos, clasificadas por materias y con posibilidad de búsqueda por palabras clave.

h) Información sobre los últimos plenos municipales, que presentan la misma tipología que en el caso anterior.

i) Enlaces a otros organismos: instituciones como las bibliotecas y archivos municipales, asociaciones de vecinos, cámaras de comercio, organismos autonómicos o centrales, proyectos europeos, proyectos locales de desarrollo, instituciones culturales, asociaciones, etc.

j) Enlaces a medios de comunicación: Algunos ayuntamientos nos ofrecen la posibilidad de enlazar con los medios de comunicación locales o nacionales (prensa, radio y televisión); otros proporcionan sus propios boletines o gacetas municipales.

Algunos ejemplos:

- A través de un organigrama, el Ayuntamiento de Madrid nos expone su estructura orgánica. Por su parte, el de Guadalajara proporciona los nombres y adscripción política de los componentes de su corporación municipal.

- El Ayuntamiento de Zaragoza permite buscar por materias y palabras clave las ordenanzas fiscales y la normativa municipal (Fig. 2). Un caso parecido es el del municipio de Vitoria-Gasteiz (Álava), que permite una búsqueda fácil y guiada de reglamentos, ordenanzas, actas y bandos municipales.

- Este último municipio, Vitoria-Gasteiz ofrece un nutrido conjunto de recursos clasificados por temas, que facilita al navegante la localización de la información que necesita.

- Trámites como la solicitud de certificados de convivencia y de residencia, de ayuda a domicilio, matriculación de vehículos, registro de asociaciones, etc., son descritos con todo detalle en el sitio web del Ayuntamiento de Córdoba. Este mismo ayuntamiento ofrece también la posibilidad de acceder a los catálogos de la biblioteca y archivo municipales. 
- Sant Cugat Obert (Barcelona) propone un kiosko de información que da acceso a la prensa local, nacional e internacional, incluso escuchar la radio local en directo. Es el caso también del Ayuntamiento de Zamora que ofrece enlaces a la prensa y a la televisión locales.

- Por su parte, el municipio de Elda ofrece la posibilidad de acceder en línea a su Gaceta municipal.

\subsection{Teleadministración}

El acceso electrónico a los servicios municipales es una de las cuestiones más interesantes para los municipios españoles en su relación con los ciudadanos. Las Tecnologías de la Información y la Comunicación constituyen unos aliados indispensables para mejorar la calidad de la prestación de servicios al ciudadano, en lo que se refiere a rapidez y eficacia, pero sobre todo para articular nuevas formas de diálogo y comunicación entre la Administración y los ciudadanos. La prestación de servicios electrónicos ofrece una alternativa para los ciudadanos, puesto que amplia los horizontes de la comunicación tradicional con la Administración, al facilitarles el acceso a ciertos servicios y permitirles cumplimentar formalidades administrativas sin tener que desplazarse. Estos servicios pueden clasificarse en dos grandes grupos:

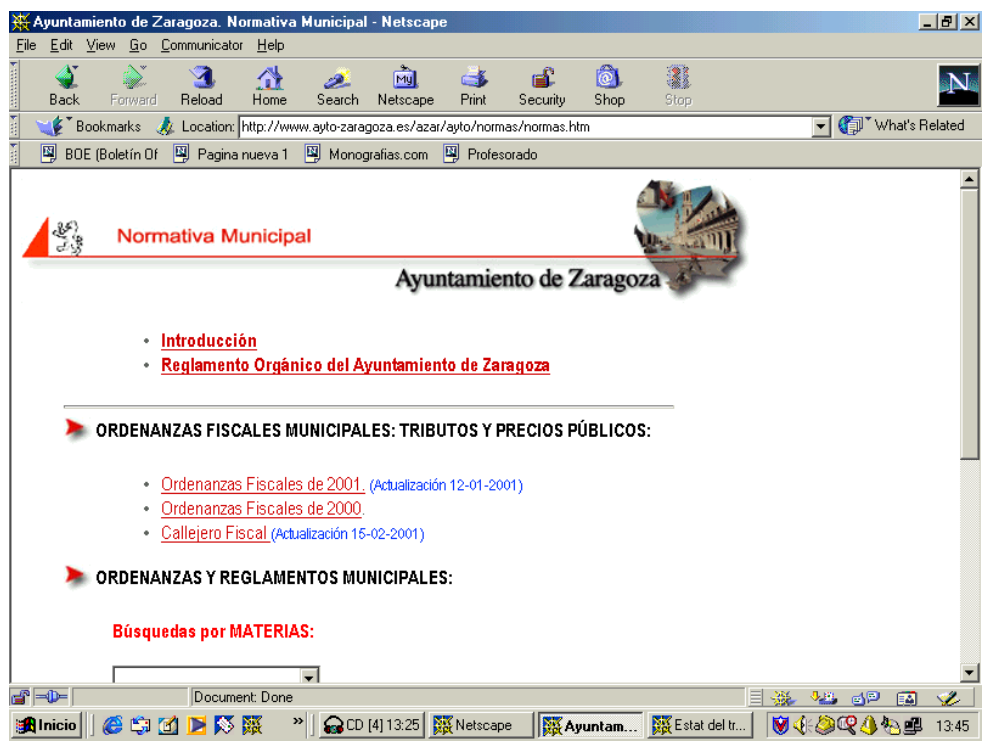

Fig 2: Normativa municipal en Zaragoza

Scire. $7: 1$ (en.-jun. 2001) 69-88. 
$1^{\circ}$ ) Aquellos - Ayuntamiento de Gijón Asturias), Ayuntamiento de Palencia- en que los ciudadanos pueden obtener a través de la red los impresos necesarios para iniciar los procedimientos, imprimirlos desde su domicilio, cumplimentarlos y presentarlos posteriormente en las oficinas correspondientes.

$\left.2^{\circ}\right)$ Los que permiten una gestión electrónica de los trámites, consultar el estado de los mismos en cualquier momento y todo ello, sin tener que someterse a horarios fijos ni a desplazamientos, todo a través de la red.

En este segundo caso, uno de los requisitos imprescindibles para poder iniciar los trámites es la identificación del ciudadano mediante una contraseña personal o número clave; con ello se garantiza al ciudadano la protección e integridad de sus datos personales de acuerdo a la ley (2). Por ejemplo, en el Ayuntamiento de El Puerto de Santa María (Cádiz) es imposible comprobar cuáles son los trámites que pueden realizarse a través de su página web, puesto que solicita una identificación previa, pero sí ofrece la posibilidad de solicitar una contraseña personal cuyo objetivo es el de no admitir una "suplantación de personalidad". En otros casos, como ocurre en el municipio de Alcobendas, los ciudadanos pueden obtener información personal y realizar gestiones municipales a través de una tarjeta electrónica que pueden utilizar desde los diversos Puestos de Información y Gestión instalados en distintos puntos de la ciudad y a través de Internet. Estas tarjetas pueden emplearse igualmente como tarjetas financieras en la red de cajeros automáticos de las entidades bancarias con las que el municipio tiene suscrito algún convenio. Las ventajas que supone este nuevo tipo de comunicación, con el formato de una tarjeta electrónica inteligente, son evidentes: reduce los tiempos de respuesta, los costes derivados del procesamiento de la información e incrementa la variedad de servicios ofrecidos al ciudadano.

Los servicios pueden variar considerablemente entre un municipio y otro, de tal modo que es posible clasificarlos desde diferentes puntos de vista. En aras de una mayor claridad, vamos a distinguir entre los servicios relativos al estado civil, quejas y sugerencias, pago de impuestos y tasas municipales, obtención de permisos y licencias, y otros servicios.

\subsubsection{Estado civil}

El sistema permite a los ciudadanos la consulta de los datos personales del padrón, tanto individuales como familiares, así como la obtención instantánea de los justificantes de padrón que éstos soliciten: certificado de convivencia, certificado de empadronamiento, certificación de residencia, altas, bajas y modificaciones de los datos de la inscripción padronal, solicitud de cambio de domicilio... Existe también la posibilidad de reservar fecha de celebración de uniones civiles en los ayuntamientos. Ejemplos de estos usos los tenemos a continuación:

Scire. $7: 1$ (en.-jun. 2001) 69-88. 
- El municipio de Madrid permite iniciar los trámites para una nueva domiciliación a través de Internet. El Ayuntamiento se encarga posteriormente de efectuar los cambios oportunos donde sea necesario, y de enviar por correo ordinario al nuevo domicilio la documentación resultante del procedimiento.

- Los municipios de Náquera (Valencia), Bilbao, Ocaña, Arnedo, Cartagena y Gijón proporcionan a sus habitantes la opción de obtener desde sus domicilios los impresos de determinados trámites administrativos. En Sabadell se puede conseguir un certificado de convivencia o de residencia (Fig. 3).

- Los ciudadanos de Cartagena que quieran celebrar su enlace matrimonial en el Ayuntamiento pueden solicitarlo cumplimentando y enviando a través de la red el formulario que proporciona su sitio web. Asimismo, las parejas de hecho que quieran inscribirse en el Registro de Uniones No Matrimoniales también pueden utilizar este medio para descargar la instancia que inicia el procedimiento.

- Desde la página del Ayuntamiento de Zaragoza es posible obtener los documentos administrativos más solicitados por los usuarios para iniciar cualquier procedimiento, así como realizarlos desde casa.

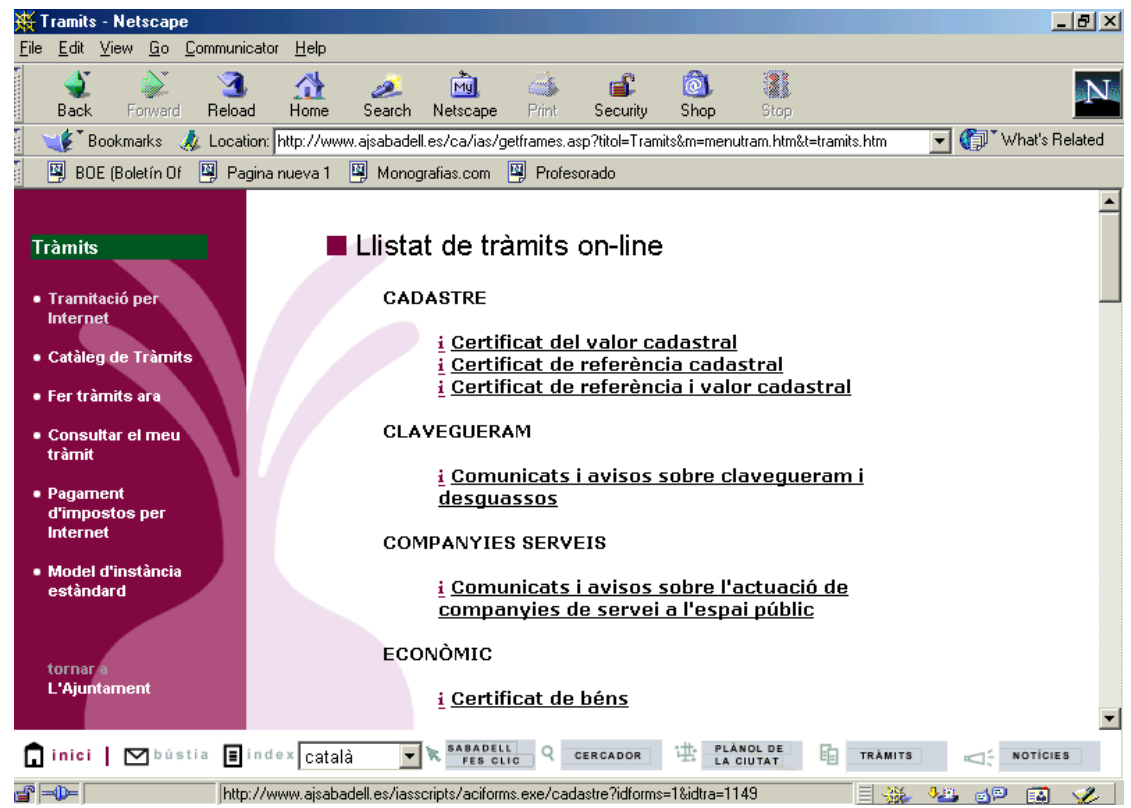

Figura 3. Catálogo de trámites on-line en Sabadell

Scire. $7: 1$ (en.-jun. 2001) 69-88. 


\subsubsection{Tributos municipales}

Se trata éste de uno de los servicios más extendidos en las páginas web que hemos solicitado. Los pagos se realizan a través de bancos o entidades bancarias, o es la oficina de recaudación del propio ayuntamiento la que se encarga de cobrarlos gracias a los datos bancarios aportados por el ciudadano en el momento de realizar el trámite. Las prestaciones abarcan otros servicios como la solicitud de domiciliación bancaria o la petición de duplicados de recibos y certificados varios. Los impuestos electrónicos suelen ser generalmente los siguientes:

- Impuesto sobre Bienes Inmuebles (IBI)

- Impuesto sobre Actividades Económicas (IAE)

- Impuesto sobre Vehículos de Tracción Mecánica (IVTM)

- Tasa por Ocupación del Vuelo, Suelo y Subsuelo

- Tasa por Paso de Vehículos

- Impuesto sobre el Incremento de Valor de los Terrenos de Naturaleza Urbana (Plusvalía)

- Impuestos sobre recogida de basuras

Algunos ejemplos de estos servicios pueden ser los siguientes:

- Los conductores de vehículos de Barcelona pueden pagar las tasas de matriculación de sus coches a través de la red, y fraccionar o aplazar el pago de los impuestos o multas municipales. Desde el sitio web del Ayuntamiento de Zumárraga (Guipúzcoa), pueden interponer recursos o adjuntar alegaciones a las denuncias de tráfico.

- Las solicitudes, alegaciones o recursos interpuestos por los ciudadanos vía Internet pueden ir acompañados por documentos digitalizados en forma de archivos adjuntos en el Ayuntamiento de Benidorm (Alicante).

\subsubsection{Obtención de licencias}

A través de este servicio, los ciudadanos pueden obtener de su ayuntamiento los permisos necesarios para realizar obras en su domicilio, para poner un puesto en el mercado semanal, para colocar pancartas en la vía pública, para realizar actividades culturales, lúdicas, deportivas, industriales, etc. En algunos municipios se pueden descargar los formularios para solicitar diferentes permisos; otros permiten hacerlo todo a través de Internet.

\subsubsection{Otros servicios}

Internet es un medio que permite a los ayuntamientos ofrecer una diversidad de servicios adaptados a las necesidades específicas de sus ciudadanos. Siendo así, cada municipio podrá proporcionar sus propias prestaciones, previamente 
atendidas las sugerencias de sus habitantes o analizadas sus necesidades informativas. Es el ejemplo del municipio de Alcobendas, que permite a sus ciudadanos reservar por Internet sus instalaciones deportivas, o el servicio de envío de postales virtuales que presenta el Ayuntamiento de Lucena (Córdoba), o también la posibilidad de inscribirse a unas pruebas deportivas enviando un formulario virtual de inscripción desde la página del Ayuntamiento de Badajoz.

Este mismo municipio dispone en sus páginas de una oficina de Telempleo, que ayuda a los jóvenes a buscar trabajo; éstos sólo deben completar datos sobre su curriculo (Fig. 4).

\subsection{Servicios de comunicación}

\subsubsection{Correo electrónico}

Todos los municipios con presencia web en la red incorporan una dirección de correo electrónico que les permite mantener una comunicación de forma interactiva con los ciudadanos. Sin embargo, hay que señalar la escasez de medios de comunicación directos con los elegidos en el gobierno municipal, lo que supondría una participación más política del ciudadano en las decisiones locales.

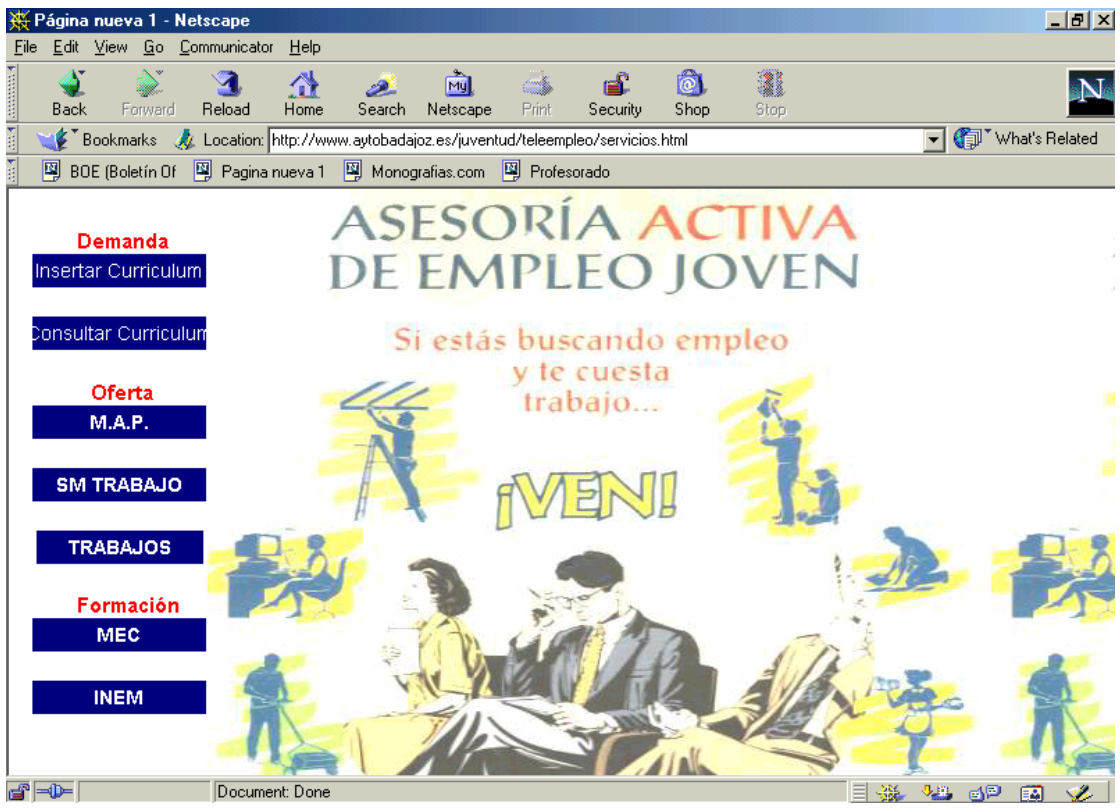

Figura 4. Oficina de telempleo en Badajoz.

Scire. $7: 1$ (en.-jun. 2001) 69-88. 
También en este apartado podemos encontrar una gama de posibilidades a la hora de ofrecer este servicio:

- La mayor parte de las comunicaciones entre el ciudadano y el ayuntamiento se realizan a través de una dirección electrónica global.

- En otros, la comunicación puede establecerse directamente con el departamento implicado, al proporcionarse un directorio de correos electrónicos.

- El ciudadano se siente atendido de forma personalizada en la página web del municipio de Olot (Gerona) al escribir sus opiniones en un formulario especialmente diseñado para el efecto.

- Una sensación similar es la que puede experimentar un residente en Barcelona que se dirige por e-mail directamente a la persona elegida por el pueblo como alcalde. Por el contrario, contar únicamente con la dirección electrónica del webmaster del sitio web resulta mucho más frío y distante para establecer una comunicación fluida y espontánea, como les sucede a los habitantes de Villa de Breña Alta (Santa Cruz de Tenerife)

- Participación plena en la toma de decisiones importantes que determinan el futuro de la ciudad es lo que pueden realizar los residentes en Manresa, ya que el Ayuntamiento incluye sus propuestas e ideas en el Plan de Actuación Municipal 2000-2003, ideas y sugerencias que pueden hacer llegar a través del correo electrónico o cualquier otro medio tradicional.

\subsubsection{Quejas y sugerencias}

Consiste en un servicio de comunicación adicional y complementario al correo electrónico entre los ciudadanos y la administración municipal cuyo objetivo es el de formular quejas, señalar anomalías que puedan existir en la vida cotidiana de un municipio o plantear sugerencias de actuación municipal, todo ello, vía Internet. Generalmente, la manera de hacer efectivo este servicio es a través de un formulario virtual diseñado al efecto donde el ciudadano puede expresar su opinión sobre distintos aspectos relativos a su municipio, y que suele denominarse buzón de sugerencias o buzón de quejas, o incluso buzón del ciudadano, como es el caso del Ayuntamiento de Alicante.

Algunos ejemplos de estos servicios se ofrecen acontinuación:

- En Polinyà (Barcelona) se puede indicar al ayuntamiento los desperfectos acaecidos en las calles, el alumbrado público, los contenedores de basuras...

- Las consultas, quejas o sugerencias pueden dirigirse directamente a cada uno de los departamentos implicados desde la página web del Ayuntamiento de Cáceres. 
- En la página web del municipio de Manresa el ciudadano puede valorar los servicios municipales mediante una encuesta de evaluación.

\subsubsection{Foros de discusión, listas de correos, chats}

La comunicación electrónica con los ayuntamientos no se reduce a los correos electrónicos. La flexibilidad de las nuevas tecnologías permite ampliar las posibilidades de articular un diálogo más amplio y participativo entre los ciudadanos y las administraciones municipales. Es por ello que muchos municipios añaden otros instrumentos de comunicación como los foros de discusión, las listas de distribución y los chats como servicios para sus administrados. En estos espacios, los ciudadanos pueden debatir acerca de los temas relacionados con la vida de su ciudad, discutir sobre la gestión de sus elegidos y, en general, acerca de aquellas cuestiones que les conciernen como ciudadanos.

Algunos ejemplos de municipios que proporcionan esta posibilidad son:

- El Ayuntamiento de Tres Cantos (Madrid) posee un servicio de foro para que sus vecinos puedan expresar sus opiniones sobre los temas de la ciudad $\mathrm{u}$ otras cuestiones que les interesen. Incluso ofrece la posibilidad al ciudadano de crear su propio foro y ser el administrador del mismo.

- Por su parte, el Ayuntamiento de Villanueva de la Cañada (Madrid) dispone de una lista de correo electrónica a la que pueden subscribirse los ciudadanos que deseen recibir toda la información cultural y de ocio relacionada con el municipio, así como las ofertas de trabajo y, en definitiva, estar informados puntualmente de todo lo relacionado con el pueblo(Fig. 5).

- El servicio de chat permite un debate en tiempo real. De esta forma, los vecinos de Écija (Sevilla) pueden utilizar este medio para participar en discusiones con otros ciudadanos preocupados por las mismas cuestiones.

\subsection{Internet}

La formación de los ciudadanos en las nuevas tecnologías de la información y la comunicación es uno de los desafíos más importantes a los que se enfrenta la Administración virtual, para conseguir esos objetivos de participación e implicación de todos los ciudadanos en la Sociedad de la Información que se está desarrollando en nuestro país, y que quedan bien reflejados en el Informe de la Comisión Interministerial de la Sociedad de la Información y de las Nuevas Tecnologías InfoXXI (Comisión..., 2000). Por ello, las páginas web de los ayuntamientos, por su cercanía a los ciudadanos, se convierten en cierto modo en una especie de "formadoras de usuarios", a la vez que actúan igualmente como puertas de entrada o iniciación al mundo de Internet, al ofrecer servicios como buscadores, alojamiento de páginas personales, formación en nuevas tecnologías, creación de páginas web, chats, y otras prestaciones que abren un mundo de 
posibilidades de información y comunicación, y que se convertirán en un futuro no muy lejano en las vías más usuales de interrelación en la sociedad.

Algunos ejemplos de estos servicios municipales se ofrecen a continuación:

- El municipio de Tres Cantos (Madrid) proporciona un completo listado de buscadores generales en su página web, para ayudar a sus visitantes a navegar en la red. Lo mismo ocurre en el sitio web de Zarautz (Guipúzcoa)

- Por su parte, el municipio de Boadilla del Monte (Madrid) proporciona un servicio de hospedaje de páginas web personales, o a asociaciones o empresas de la localidad que quieran utilizar el sitio web municipal para hacerse conocer.

- Resulta interesante el servicio de Internet que ofrece la página de Zumaia (Guipúzcoa) a un precio reducido.

- El servicio de FTP en la localidad de Écija (Sevilla), que permite descargar programas de música, editores de lenguaje HTML y otras utilidades. También proporciona un servicio gratuito para enviar mensajes a móviles.

- El municipio de Andoain (Guipúzcoa) ofrece una dirección de correo electrónico a todos los ciudadanos que la soliciten. También este es el caso de

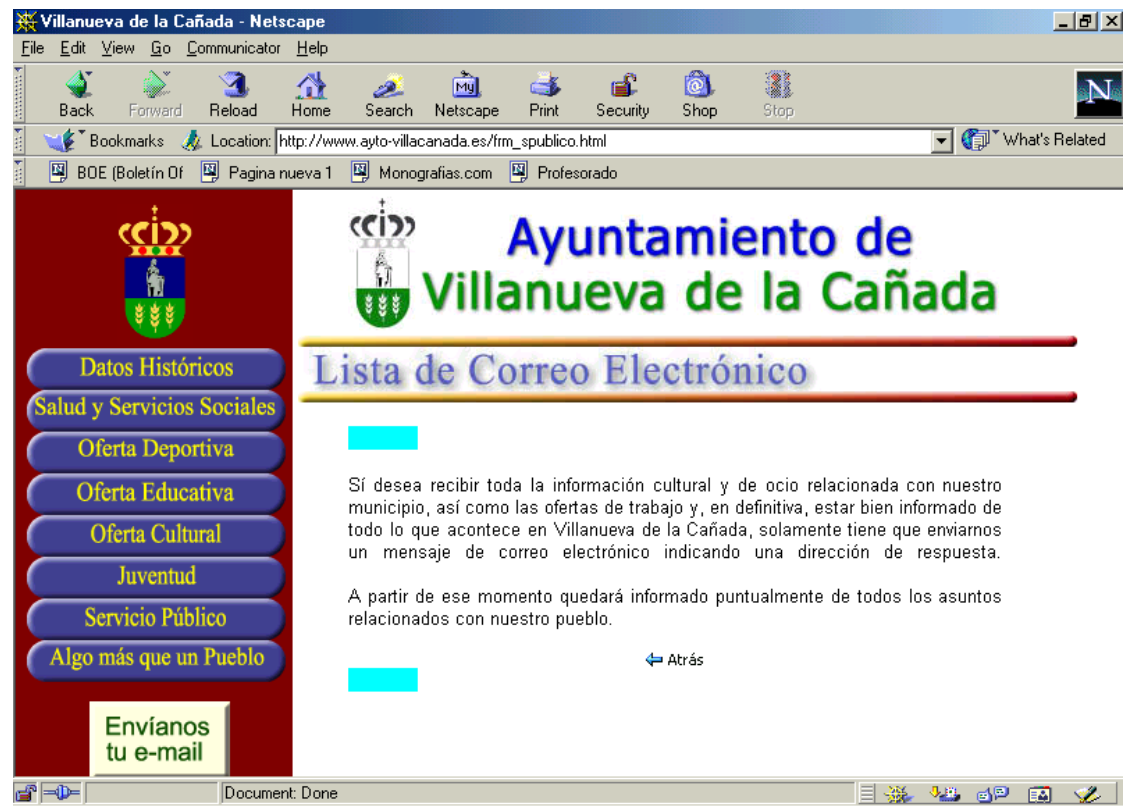

Figura 5. Lista de correo del Ayuntamiento de Villanueva de la Cañada

Scire. $7: 1$ (en.-jun. 2001) 69-88. 
Manresa, ya que el Ayuntamiento proporciona una dirección de correo electrónico a sus vecinos, que pueden utilizar como medio de comunicación con su gobierno local a través de los Puntos Públicos de Internet distribuidos por toda la ciudad, y recibir en su buzón electrónico, si así lo desean, un Servicio Periódico de Información sobre temas relativos a la vida en su colectividad.

- Algunos ayuntamientos, como el de Figueres (Girona) o Sabadell (Barcelona) (Fig. 6) introducen a sus habitantes en los conceptos básicos de la Sociedad de la Información, proporcionando documentos informativos sobre esta cuestión con el objetivo de promover la utilización de las tecnologías de la información entre los ciudadanos y dar a conocer los planes municipales para el acceso público a la red de forma gratuita y la creación de "ciudades virtuales".

- Las páginas web de algunos municipios son el ámbito idóneo para estimular la creación de redes ciudadanas y concienciar de la importancia de la generalización en el uso de las nuevas tecnologías para comunicarse y organizarse. Es el caso de los ayuntamientos de Sabadell y Cuenca, que ofrecen la posibilidad de participar en estas redes.

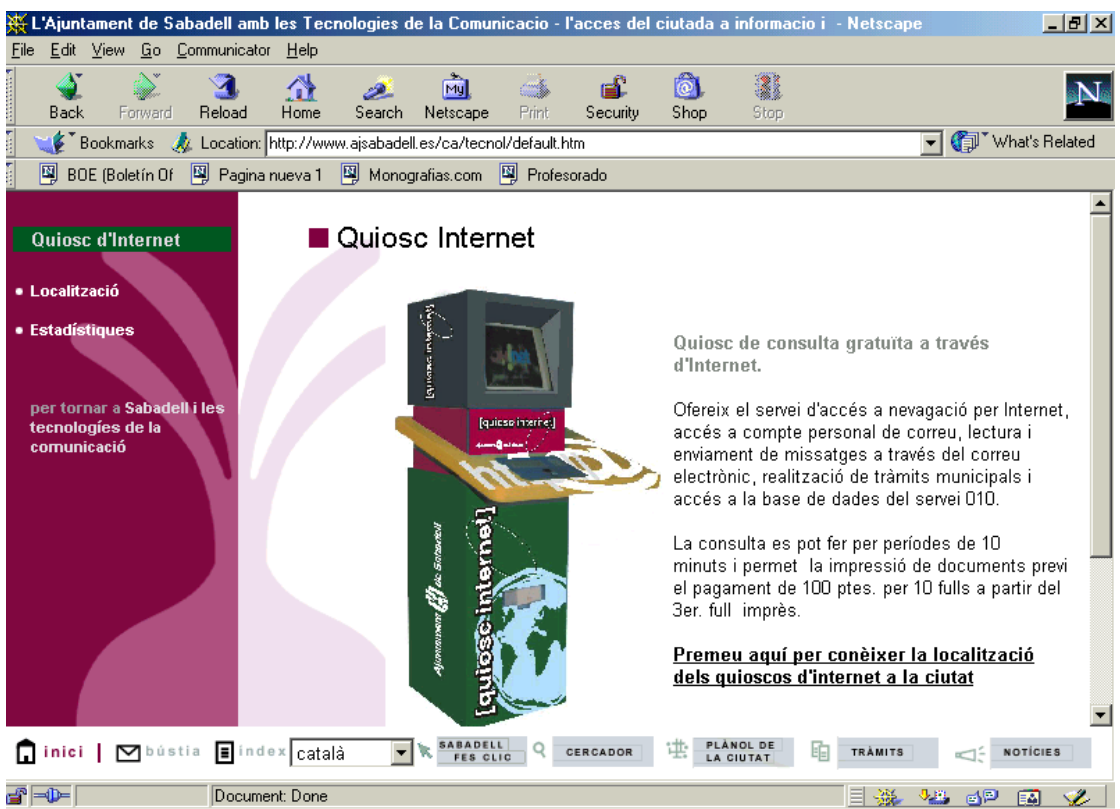

Figura 6. Quioscos públicos de acceso a Internet en Sabadell

Scire. $7: 1$ (en.-jun. 2001) 69-88. 


\section{Conclusiones}

- Este estudio demuestra que las políticas municipales apuestan por la difusión electrónica de la información municipal y los teleservicios. Cada vez en mayor número, utilizan el formato de la página web para proporcionar información a los ciudadanos, por lo tanto son conscientes de la capacidad informativa y comunicativa de la Red.

- Además de la potencia comunicadora de la Red, otros motivos de índole económica refuerzan el desarrollo de las TIC en las administraciones públicas. Se trata de la importante reducción de costes que supondría la implantación de una Administración sin papeles, aunque indudablemente la inversión en tecnología sería bastante considerable en las primeras fases.

- Por otra parte, se trata de un medio idóneo para fomentar el espíritu democrático y la participación de los ciudadanos en la gestión de los asuntos públicos. Las páginas web de los municipios se convierten en definitiva en "espacios de ciudadanía" donde los ciudadanos pueden implicarse en la vida de su localidad gracias a los medios tecnológicos.

- El contacto privilegiado que las comunidades locales mantienen con los ciudadanos las convierten en una plataforma fundamental para extender y estimular entre los ciudadanos la utilización de las nuevas tecnologías de la información y la comunicación. Por lo tanto, los municipios desempeñan una labor fundamental en el desarrollo e implantación de la Sociedad de la Información en nuestro país (Pratchett, 1998). Por todas estas razones desde los poderes públicos se potencia el desarrollo de las TIC tanto a nivel estatal, como autonómico y local.(3)

Sin embargo, la implantación de las TIC en las colectividades locales plantea también algunos problemas. Entre ellos, podríamos mencionar los elevados costes que supone la dotación de equipamientos informáticos y la adecuación de las infraestructuras tecnológicas para hacer posible el funcionamiento generalizado de la Sociedad de la Información (4), la organización y planificación de actividades de formación, dirigidas tanto al personal público como a los ciudadanos, así como la necesidad de asegurar las transacciones y las comunicaciones electrónicas de los ciudadanos con sus ayuntamientos.

\section{Notas}

(1) Real Decreto 670/1999, por el que se crea la Comisión Interministerial de Simplificación Administrativa, que lleva a cabo el Plan General de Simplificación en la Administración General del Estado con reducción de procedimientos y trámites.

(2) Las figuras que están surgiendo para asegurar la confidencialidad y fiabilidad de las transacciones y comunicaciones a través de la red son la firma y la certificación elec-

Scire. $7: 1$ (en.-jun. 2001) 69-88. 
trónica. Véanse al respecto el Real Decreto-Ley 14/1999, que regula el uso de la Firma Electrónica, y el Real Decreto 1290/1999, que regula la prestación al público de servicios de certificación por la Fábrica Nacional de Moneda y Timbre. Véase también el proyecto TASS, bajo la responsabilidad de la Fábrica Nacional de Moneda y Timbre, encargada de la producción, personalización y distribución de estas tarjetas. http://www.fnmt.es/tarjetas/Proyectos/ceres.htm (consultada en octubre de 2000), y el proyecto CERES (CERtificación ESpañola), y que consiste, en líneas generales, en "establecer una Entidad Pública de Certificación, que permita autentificar y garantizar la confidencialidad de las comunicaciones entre ciudadanos, empresas u otras instituciones y administraciones públicas a través de las redes abiertas de comunicaciones".

(3) La organización Admiweb convoca premios al mejor sitio web como reconocimiento a los esfuerzos de las administraciones públicas en el desarrollo de páginas web de atención al ciudadano (URL=<http://www.admiweb.org $>$ ).

(4) Respecto a esta cuestión puede consultarse el dossier realizado por: Rodrigue (1997).

\section{Bibliografía}

Brugué, Q. ; Amorós, M. ; Goma, R. (1996). La Administración Pública y sus clientes: ¿Moda organizativa u opción ideológica?. // Castillo Blanco, F. (Dir.). El ciudadano y la administración. Cuadernos de Documentación e Información. 80 (1996) 403-416.

Comisión Interministerial de la Sociedad de la Información y de las Nuevas Tecnologías ( 2000). INFO XXI: La Sociedad de la Inform@ @ión para todos. Primera fase 20002003. Enero, 2000. Disponible en URL=<http://www.map.es>

López García, Liborio (2000). La gestión del conocimiento en el Ministerio de las Administraciones Públicas. // Gestión del conocimiento y capital intelectual: Experiencias en España. Madrid: Comunidad de Madrid, Instituto Universitario Euroforum, 2000. 48-49.

MAP (2000). Libro blanco para la mejora de los servicios públicos: una nueva Administración al servicio de los ciudadanos. Madrid : MAP, 2000.

Pratchett, L. (1998). Technological Bias in an Information Age: ICT Policy Making in Local Government. // Snellen, I. Th.M. ; Van de Donk, W.B.H.J. (eds.) Public Administration in an Information Age: A Handbook. Amsterdam : IOS Press; Ohmsha, cop. 1998. 207-219

Réseau d'observation de l'utilisation des technologies de l'information et des inforoutes dans le secteur publique (Réseau OUTI)(1997). URL: <http://www.enap.uquebec.ca/ Observatoire/OUTI>.

Rodrigue, J.-P. (1997). Les coûts, bénéfices et/ou impacts de l'implantation d'une autoroute de l'information dans les administrations publiques. // Réseau d'observation de l'utilisation des technologies de l'information et des inforoutes dans le secteur publique (Réseau OUTI), 1997. URL: =<http://www.enap.uquebec.ca/Observatoire/ OUTI/coutsTI.html>. 